patient was a woman aged forty-eight. Six years ago she had been attacked with fits, and had "scores" of them every day -at least twenty in twenty-four hours. During the whole six years she was only once free of them for fiur days. She must, therefore, have had at least 6000 fits altogether. When I first saw her she had an attack in my consulting. room, and I confess it was the most terrible attack I have ever witnessed. She was treated by means of hypodermic injections of morphia, and in the week after the injections she had only one attack. The injections were repeated twice a week, and when the attacks were turned into "faintings," as the patient called them, which recurred about three or four times a week, and did not cause her to fall, she did not return to the hospital any more.

Of the whole number of my patients, 46 remained sufficiently long under treatment to wariaut an opinion of the efficacy of the drugs applied. Of the number just mentioned, 14 were cured, 26 have improved, wbile in 6 the treatment had no effect. A case which I am inclined to look upon as cured is the follow ing:- The patient was twenty-one years old, a shoemaker by trade. The grandfather had several tits, but the patient was in good health until three years before he came under my care. At that time he came up from the country, in order to see an execution at Newgate, which made such an impression on him as to bring on evileptic fits after a few hours. In these fits he lost consciousness, and was very much convulsed. For two years be was sometimes free from paroxysms for several months, and then again he had several attacks in the course of a day; six months, however, before he was admitted an out-patient to the hospital, he was seized several times every day. He was likewise treated by means of hypodernic injections of morphia, which were continued for a long time. After having been free from attacks for about twelve mouths he requested me, in 1865 , to discharge him, in order that he might go in search of employment. A few months ago bis father came to the hospital, and from him I learnt that his son, who is now in the country following his trade, had never had a fit since be left the hospital.

As to the remedies used by me for the treatment of epilepsy, I have tried nearly all drugs which have been recommended by different authors, including urari or the arrow-poison of the Indians, so strongly recommended by a few continental physicians, which, however, has failed in my hands. *

But there are two drugs in which confidence may be placed, viz., bromide of potassium and hy podermic injection of morphia. It is now a well-known fact, that the former, when used in very large doses has the power of postponing the paroxysms, and, in some instances, to make them disappear altogether. Hypodermic injections have the power of prolucing the same result in a much shorter time. It is very difficult to explain why the action of morphia is different when given internally and when applied hypodermically, but that such is the case has been confirmed by reliable observers.

Finsbury-square, Dec. 1868.

\section{DR. LAUDER LINDSAY'S "PROTECTION BED" IN THE TREATMENT OF THE INSANE.}

\section{To the Editor of THE LANCET.}

SIR,-In Dr. Conolly's last work + he dwells with anxious solicitude on the future of the non-restraint system, and states (as he often did in conversation with me) bis fears lest in the coming years, when he had gone to his rest, it might perchance be abaudoned, imperfectly acted upon, or misrepresented by those who knew not, from personal observation, of the horrors of the old restraint system. "I am anxious (be writes) in these pages to explain, as distinctly as $I$ am able, the nature, as well as the rise and progress of the method of treating the insane, which is commonly called the 'Non-restraint System,' so as to contribute to its preservation and further improvement, and perhaps to its wider adoption; or, at least, to prevent its being abandoned, or imperfectly acted upon, or misrepresented, when those by whom it has been steadily maintaived in its early days of trial and difficulty can no longer describe or defend it."

Dr. Conolly's fears are almost realiserl in the following remarks, to which my attention has just been directed in a paper "On Typhomania." by Dr. Lauder Lindsay, in the Edinburgh Medical Journal, Ottober, 1868. I quote the passane in full:-

* The results of my experimerts with urari have bi en published in "The Journ ,l of An frimy id Phvsiol gy." 1868.

+ "The Treatment of the Insane, without Mechanical Restraint." London,
"Use of the 'Protection Bed,' otherwise variously known as the 'Box Bed,' or 'Locked Bed.'-In siwalar cases to the foregoing, in patients with systems reduced to the verge of disso. lution by disease, whether acute or (as is more common) chronic-where there is danger from the exhaustion consequent on the simple effort to get out of bed, or the scarcely less immediate risk from exposure to culd-where, moreover, the patient bas an uncontrillable propensity to get out of bed, and expose himself to talls and to cold-there is no arrangement comparable with the bed in question. It is simply a bed with a lid-to be locked or not, as the case may require. It may thus be rendered impossible for the patient to get up or out thereof without permission of his attendant. Its use renders him quiessent for the time, while it maintains warmth and does not prevent free ventilation. I have reptatedly tried it in various forms, and have no doubt as to its having pro. longed several lives, and prevented many accidents, that would have been sacrificed, or that would have occurred, under the customary arrangements of many or most other asylums. Such is my opmion of its usefulness that I think it should find place, not only in every lunatic asylum, but in every general hospital; for I remember the difficulties that used to occur in (e.g, the fever and delirium tremens wards of) the Royal Infirmary of Edinburgh, and the impossibility of dealing with occasional patients otherwise than by mechanical restraints of the nature of strait-waistcoats and strappings to bed. Unfortunately for its usefulness, however, the box bed is somewhat unsigbtly; while many asylum authorities, who do not consider confinement in an asylum or a bed-room " re. straint,' inconsistently place in that category an appliance which differs only in degree, not in kind; they prefer, apparently, to give a blind adherence to a principle, which, how. ever good in proper time and place, may be, and is sometimes, carried mischievously to an extreme, rather than, independently of all other considerations, to reyard what is the best treatment in and for the case of each individual patient. The 'Protection Bed,' so called by Dr. Browne, Commissioner in Lunacy for Scotland, was for many years by him employed in Crichton Royal Institution (for the Iusane), Dumtries, where it is still used by Dr. Gilchrist, by whom, further, it was also employed in the Royal Lunatic Asylum, Montrose. Dr. Alexander Robertson, of the Town's Hospital, Glasgow, who has lately visited the United Statez, informs me that the said bed is extensively used in the lunatic asylums of that country; and the fact that it is so used by physicians so advanced, amidst a people so enlightened as those of America, seems to me a strong argument in favour of its presumptive usefulness. There is, however, little hope of its general employment in Eugland until asylum suptrintendents throw off the terrorism that exists of the Lunacy Board and 'Restraint'-until they cease to be influenced by a mere name, and are sufficiently independent to do what, under any given circumstances, their conviction tells them is the right thing. There is, too, frequently a tendency to do what is supposed to be acceptable to the Board of Lunacy or Board of Directors, to public opinion or the press, to the patient or his guardians, rather than, as independently (as may be) of all other considerations, to do what is best for the given patient under given circumstances."

Dr. Lauder Lindsay appears here to think that "the terrorism of the Lunacy Board and of Restraint" militates against the general employment of his invention (the Protection Bed) by the Medical Superintendents of the Euglish County Asylums. I have more than once ventured to speak with authority as their representative; and here $I$, in their name, repel the shallow impertinence which would argue that our neglect of this supposed iuvention arises from the influence of the Commissioners in Lunacy on our theory and practice. The English Superintendents worked out the non-restraint system before it was formally adopted by the Commissioners, and they will abide by their protest against all restraint in the treatment of the insane so long as their Houses stand. It is, indeed, terror which binds them to thelr standard; but their terror is of the influence of traitors in the camp, who would undermine the great structure of non-restraint, which they have for long years so diligently and lovingly built up, which they have, against all comers, defended, and which they yet trust to hand untaruished to their successors in office.

You recently, Sir, aided with the support of THE LANCET the efforts of the editors of the Journal of Mental Science to oppose the introduction into practice at the great Metropolitan Asylum at Colney Hatch of Dr. Sheppard's theories of the treatment of a "certain class of destructive patients," which we believed to be opposed to the principles of the non-restraint system. Dr. Sheppard proposed to remove al clothing and 
eare from this class of patients, and to place them in empty cells; Dr. Lauder Lindsay takes the directly opposite view, and would lock the patients, clothing and all, into his box beds-instruments of restraint similar in construction, and less soothing in practice, than the bain de force still seen in al French asylums. I commend Dr Sheppard's clever defence of his theory (Journal of Mental Science, April and October, 1867) to Dr. Lauder Liudsay's perusal.

Dr. Lauder Lindsay has apparently yet to learn that the successful treatment of the non-restraint system is based on the very opposite principle from that which guided the small inventive faculty of the originators of strait-jackets, strongchairs, leg-locks, and which has culminated in the Protection Bed. All these contrivances belong to a system of treatment extinct in the English County Asylums. Their fall may be traced in Dr. Cunolly's chapter, "The last days of the old method of treatment." Their final condemnation was thus summarised by him:-"No fallacy," he writes, "can be greater than that of imagining what is called a moderate use of mechanical restraint to be consistent with a general plan of treatment in all other respects complete and unobjectionable and humane." Dr. Conolly, indeed, without knowing of the Protection Bed, sketches in his next chapter its baneful influences:-

"In the greater number of recent cases of mental malady, the patient is unable to sleep; the days are tolerably tranquil, but with the night restless distraction comes. Whoever has known the affletion of a restless night must know that his affliction would have received no abatement from his being tied down to his bed; and that fresh air, cold water, sitting up a while, and diversion of mind, are the things to which he would resort for relief. The poor lunatic, equally restless, equally sleepless, and with a brain more excited, should not be deprived of these alleviations, all of which form a part of the non-restraint system; but none of which are regarded where restraints are employed, which are, indeed, utterly incompatible with them. The attendant who has fastened down his troublesome and sleepless patients in bed, retires with a satisfied mind to his supper and his rest. The patients may suffer from heat and thirst, and may shout and yell in their despair. He heeds them not; or, if he does, it is only to visit them in an angry mood, and to punish them as he chooses. The attendant, where restraints are not used, cannot leave his patients so neglected, or punish them at will. The physician himself, in large asylums, frequently goes round the wards at night, and a system is established by which their state is re ported to him every morning. If a patient cannot lie down without distress, be is not cimpelled to lie down, but allowed to walk about; being supplied with soft, warm shoes, and other clothing, to prevent his suffering from being out of bed.

If he knocks at the door of his room, the reason of his doing so is inquired into; if he is thirsty, he has water given to him; if he has been restless, and his bed is discomposed, the bed is made comfortable again; the patient's face and hands are cooled with water; perhaps a cup of tea, or coffee, or beef-tea, or arrowroot, kept in readiness by the night attendant, is given to him, or sometimes a little tobacco, and thus the patient is refreshed in body and sootbed in mind, blesses his visitors, bids them good night, and falls asleep; and thus the cries and howls which disturbed the wards so often are heard no more.

"The old system placed all violent and troublesome patients in the position of dangerous lunatics. The new system regards them as afflicted persons, whose brains and nerves are diseased, and who are to be restored to health and comfort and reason. This simple difference of view it is which influences every particular in the arrangement of every part of an asylum for the insane"

I cannot conclude this letter without expressing my sincere regret that Dr. Lauder Lindsay should bave thought fit in bis last report of Murray's Royal Asylum, Perth (1865.68), when introducing this protection bed to the notice of the committee (as the only special appliance or mode of treatment which it seemed to him desirable to mention as being apparently little known, or used in British asylums), to renew his suggestion that servile fear of the Lunacy Commissioners, a fear which he says reigns among all classes of officers in British asylums, stands in the way of its introduction into the English county asylums.

I must, in conclusion, say for myself that I little thought the self-invited guest, to whom I once endeavoured here to show such poor hospitality as lay in my power, and to afford such information as he sought at his visit, was weighing my servile fears in his lofty balance, and noting the weakness which would probably prevent the introduction with us of his ew method of restraint. At any rate, a servile fear of in inging the requiremeuts of good nıanners and professional courtesy cannot be retorted against Dr. Lauder Lindsay.

I am, Sir, y. ur ohedient servant, C. Lockhart Roberisson, M.D., F.R.C.P.

Hayward's Heath, Sussex, December 81 h.

\section{THE SCIENTIFIC INVESTIGATION OF CHOLERA.}

To the Editor of Tere Lancet.

SIR,-Conceiving that the information contained in the enclosed documents may prove interesting to other inquirers in the same direction, I have much pleasure in placing them at your disposal, instead of retaining them for publication in the next annual departmental blue-book.

Owing to the generous interest of the War Office authorities, we have been enabled to send out to India, at the suggestion of the Senate of the Army Medical School at Netley, two officers belunging to the Iudian and British medical services respectively, who are fully qualified to enter upon the study of the fungoid bodies which, it is asserted, exist in the excreta of cholera patients, and to determine the truth or otherwise of the bypothesis which assigus a causative relation between the presence, growth, and dissemination of these bodies, and the origin and development of choleraic disease. The views entertained by Professor Pettenkofer, in regard to the influence exercised by the permament characters or varying conditions of the soil during the seascns when epidemic cholera prevails, will likewise form part of the inquiry; and with this view the medical officers in question have been instructed in the best methods of observing and recording the changes in the level of the ground-water, the temperature, amount of moisture, and decomposing organic matters present in the soil.

These subjects, in common with others-such as a repetition and extension of Dr. Burdon-Sanderson's experiments-will devolve upon those entrusted with the study of the more purely scientific aspects of the inquiry. There are, however, besides these, a large number of questions of a less technical character, which will form part of the investigation that the bome authorities are desirous of instituting in India, and in the pursuit of these we hope to bave the co-operation of medical officers generally in that country. An epidemic of comparatively recent date, but, unfortunately for the soldier, not of unusual occurrence, has lately attracted a considerable degree of attention, and it is a matter of gratification to find that the Imperial power which holds India shuuld enter on a thorough and systematic registration and investigation of all the facts connected with cholera, with the hope that we may find some means of limiting its ravages.

I have the honour to be, Sir, your obedient servant, T. G. LogaN, Lirector-General.

\section{THE ACOUOXYLON.*}

To the Editor of THE LANCET.

Srr,-In your journal of last Saturday, December 19th, under the communication of Dr. Paul Niemeyer on the "Aconoxylon," you remark in the foot-note, "These solid stethoscopes have not been found especially advantageous; their chief defect is, that they are heavier than bollow ones, \&c." We beg to state that, at the suggestion of Dr. B. W. Foster, of Birmingham, we have made a solid cane stethoscope weighing ouly about balf an ounce, a weight considerably lese than that of nost stethoscopes ; it also possesses the ad vantage of great conducting power, and is not easily broken. The end applied to the chest is made oval, to enable the auscultator to obtain a more exact apposition between the pibs. We ex hibited this stetboscope at the Oxford Meeting of the British Medical Association. We are, Sir, yours obediently, Grafton-street, Dec. 22nd, $1868 . \quad$ J. COXETER AND SON.

* By an error of the press, Dr. Niemeyer's word was last week misprinter "Aconoxylon."-ED. I. 